\section{Anonymous Reviews-Are the Pros Worth the Cons?}

\author{
Alexander McBirney, \\ University of Oregon
}

One of the practices that is said to have stimulated science in the western world is the open criticism of our work and free debate in the forum of refereed journals. It is this dialectical exchange of views that has ensured the accuracy of our observations and the logic of our conclusions. Today, however, we have a system in which little if any of this exchange appears in the pages of our journals. Instead, it takes place before publication in a review system that is designed to correct errors and clarify our writing before it appears in print. To do this, an editor, who may or may not be conversant with the subject of the paper, selects a set of reviewers whose identity is usually unknown to the author. On this basis, a judgment is reached, and an author may be told that his work is unacceptable or cannot be published unless certain parts are altered in accordance with the views of a secret reviewer.

Similarly, our proposals requesting support for research are evaluated by a group of our peers who are considered qualified to judge the merits of our work. In recent years, this critique has been carried out entirely by anonymous reviewers, the rationale being that anonymity permits reviewers to express their judgment unconstrained by fears of offending a friend or someone who might react vindictively.

Most of us would agree that, on the whole, this system for reviewing journal articles and proposals has worked fairly well. It would probably be ideal if all of us were courteous, rational humans free of emotion and immune to subjective influences. Unfortunately, we are not. Too often, an anonymous review brings out the worst in both its author and its recipient. In the worst cases, anonymity is taken as a license to make demeaning remarks or unfounded accusations that in many instances do not even address the substance of the paper or proposal. We have all received-and some of us have written-rude, patronizing reviews that would be unthinkable if the reviewer were faceto-face with the target of such insults. There are any number of reasons why we do this:

- It offers a chance to settle old scores.

- It is a way of putting down an arrogant "authority" in our field.

- It is an emotional reaction to new ideas the reviewer finds disturbing.

- It reduces the competition for limited research funds.

- It enables us to sidetrack work that may render our own obsolete.

Ironically, reviews are not held to the same standards of objectivity as the papers they address. Statements require no supporting evidence, and twisted logic can pass unchallenged. A good editor or program director will recognize a biased review and discount it, but who can dismiss the judgment of a person who is considered an expert in the field of work in question? The slightest reservation expressed by such an authority can be fatal. When considering the value of peer reviews it is worth remembering that the leading playwrights working in London at the time considered Shakespeare a mediocre hack.

Editors or National Science Foundation panels can, and often do, exercise their own judgment and weed out offensive or unhelpful reviews, but anyone who has been in such a position will acknowledge that it is easy to influence the fate of a paper or proposal simply by making an appropriate choice of reviewers. We may not admit it, but it is common practice to select reviewers that can be counted on to give a desired judgment. To this end, many editors keep at least one person on their team who can be depended on for a negative review, regardless of the merits of the paper.

In a purely philosophical sense, the anonymous review violates one of our most basic democratic principles. A fundamental rule of our justice system holds that one who is being judged has the right to confront his accusers. This right is denied when a verdict is rendered in secret on the basis of testimony from unidentified individuals selected by a process in which one cannot participate. In any court of justice, one has the right to know and challenge the qualifications or objectivity of witnesses. Why should it not be so in science?

To the extent that this situation is becoming unsatisfactory, if not intolerable, it is certainly worth considering alternatives. An increasing number of reviewers have already resolved not to conceal their identity. Even with National Science Foundation reviews that will not bear their name, reviewers insert a comment or reference that serves to identify them. Following this approach forces one to ensure that the review is objective, carefully reasoned, and free of belittling comments. There are times, of course, when one is tempted to go back on this resolve, particularly when a paper or proposal submitted by a good friend fails to meet the standards one would expect, but with a little effort, one can convey a negative opinion in a courteous, constructive manner. By explaining where the work is faulty and suggesting remedies, it is possible to show that the intent is to be helpful.

It may be unrealistic to propose that anonymous reviews be totally abandoned. For one thing, it would certainly make the editors' task of finding reviewers more difficult. Even if a person does not object in principle to being identified, a signed review demands much more of time and effort and a busy person may be reluctant to evaluate a paper or proposal that may require several hours to review properly. But isn't that exactly what one has a right to expect? Anyone who has devoted months, if not years, to a piece of work deserves nothing less.

Judging from the views of various friends with whom I have discussed the problem, it seems that most would agree that we need fewer hasty, off-the-wall opinions and more constructive suggestions for improving our work. Perhaps we could set as a minimal requirement that a review must be a courteous, constructive, and objective assessment of the major points the author is striving to make. By adhering to such a simple rule, which, after all, is nothing more than normal civilized conduct, we could save ourselves a good deal of grief and wasted energy. 